\title{
OBSERVAÇÕES SOBRE A SEMIÓTICA DE SANTO AGOSTINHO
}

\author{
OBSERVACIONES SOBRE LA SEMIÓTICA DE SAN AGUSTÍN
}

\author{
Carina Kilian* \\ Jorge Alberto Molina**
}

\section{RESUMO}

Neste trabalho analisamos diferentes aspectos do conceito de signo em Santo Agostinho. Primeiramente, dissertamos sobre os sentidos que Agostinho outorgou ao termo "signo". Depois, nos debruçamos sobre o diálogo Do mestre, mostrando que este contém uma teoria sobre a linguagem como sistema de signos da qual se conclui a impossibilidade de aprender ou ensinar por meio de palavras. A seguir, voltamos a Da doutrina cristã e mostramos como Agostinho, unificando diversas tradições que se ocuparam dos signos (lógico-semântica, retórica e hermenêutica) desenvolveu uma teoria geral sobre eles, dentro da qual a linguagem verbal aparece como um sistema de signos ao lado de outros códigos semióticos como os dos gestos e das pinturas, mas que possui, no entanto, um poder de expressão maior. Por fim, exploramos, também em Da doutrina cristã, as relações entre a Semiótica contida nessa obra e a Hermenêutica dos textos sagrados, com destaque para as figuras de linguagem, tendo em vista que Santo Agostinho foi também professor de Retórica. Como resultado, observamos que Santo Agostinho foi o primeiro autor latino que se ocupou da palavra como signo, inaugurando a Semiótica no Ocidente, embora sem uma nomenclatura detalhada acerca dos conceitos que envolvem a linguagem como conhecemos hoje.

PALAVRAS-CHAVE: Agostinho. Linguagem. Signo. Semiótica e Filosofia da Linguagem. Retórica.

\section{RESUMEN}

En este trabajo analizamos diferentes aspectos del concepto de signo en San Agustín. En la primera parte disertamos sobre los diferentes sentidos que ese autor dio al término "signo". En la segunda parte, mostramos que el diálogo Sobre el maestro contiene una teoría sobre el lenguaje como sistema de signos a partir de la cual se concluye la imposibilidad de aprender o enseñar por medio de palabras. En la tercera parte, retornamos a Sobre la doctrina cristiana y mostramos que San Agustín, unificando varias tradiciones que trataban de los signos desarrolló una teoría general sobre ellos, dentro de la cual el lenguaje aparece como un sistema de signos diferente de otros códigos semióticos por poseer un poder de expresión mayor y poder se referir a si mismo. En la cuarta parte, buscamos relacionar la Semiótica contenida en esa obra con la Hermenéutica de los textos sagrados, deteniéndonos en particular en la función de las figuras del lenguaje. Como conclusión observamos que San Agustín, fue el primer autor en lengua latina que concibió la palabra como signo, fundando así la Semiótica en Occidente.

PALAVRAS-CLAVE: San Agustín. Lenguaje. Signo. Semiótica y filosofía del lenguaje. Retórica.

\footnotetext{
* Mestre em Letras pelo Programa de Pós-Graduação em Letras: Leitura e Cognição da Unisc. Atualmente é professora de Língua Portuguesa nos municípios de Paraíso do Sul e Santa Maria, RS. E-mail: carinakilian1@yahoo.com.br.

** Doutor em Lógica e Filosofia da Ciência pela UNICAMP. Professor Adjunto da Universidade Estadual do Rio Grande do Sul. E-mail: jorge-molina@uergs.edu.br.
} 


\section{AGOSTINHO E O TERMO SIGNUM}

Os signos têm diferentes abordagens segundo as acepções dos autores. Em linhas gerais, eles podem ser verbais e não verbais. Os não verbais funcionam como indícios ou sinais de algum fato, enquanto os verbais reportam os fatos por meio das palavras. Nosso estudo buscou compreender como Agostinho abordou os signos verbais e não verbais nas obras Do mestre e Da doutrina cristã. Porém, ao pesquisar suas obras, observamos que ele foi além em suas reflexões, isto é, abordou não somente os signos (o que lhe dá o status de o primeiro autor do Ocidente a elaborar uma teoria geral sobre eles), como compilou o texto $\mathrm{Da}$ doutrina cristã um verdadeiro manual de exegese bíblica, tornando-a também uma obra sobre como ensinar e praticar a doutrina cristã.

Na obra Da doutrina cristã, três tarefas levaram Agostinho a se ocupar da linguagem. A primeira consistiu em construir uma teoria sobre o conhecimento que temos de Deus, das realidades inteligíveis e de nós mesmos; a segunda, em propor uma hermenêutica das sagradas escrituras; e, finalmente, em apresentar uma retórica religiosa, um discurso sobre como pregar a religião cristã.

Segundo Todorov (1996), a originalidade da abordagem agostiniana à linguagem reside, entre outras coisas, no fato de tê-la considerado um sistema de signos. Dessa forma, segundo auquele autor, Agostinho teria sido o fundador da Semiótica no Ocidente, se entendermos por Semiótica uma teoria sobre os diferentes tipos de signos (sinais) ${ }^{1}$ e não apenas sobre as palavras. Horn (1995, p.88), porém, remarca que já Aristóteles, no De interpretatione (1995, I, 16a), considerara as palavras como signos de representações mentais, as que, por sua vez, simbolizam as coisas representadas. Contudo, pode-se afirmar com certeza que Agostinho foi o primeiro autor de língua latina em usar a palavra signum para falar das palavras (verba) e em considerar estas últimas como uma espécie do gênero dos signa.

O que chamamos de Semiótica de Agostinho encontra-se apresentado, principalmente, em três obras: um tratado de juventude, Da Dialética, escrito em 387; o diálogo Do mestre (De magistro), composto em 389; e o texto Da doutrina cristã (De doctrina christiana), um manual de exegese e formação cristã, cujos primeiros três livros foram escritos em 397 e que

\footnotetext{
${ }^{1}$ Agostinho usa o termo latino signum. A tradução de Ricci do De mestre o traduz como sinal. Da mesma forma o traduz Assis Oliveira na sua versão do Da doutrina cristã. No nosso texto, usaremos "signo" e "sinal" segundo nos pareça mais apropriado. Em português há sutis diferenças de sentido entre "signo" e "sinal". Agostinho usa signum para expressar o que nós queremos dizer com essas duas palavras.
} 
Agostinho só veio a terminar em 426 ou 427, anexando treza capítulos ao terceiro livro e compondo todo o quarto. Neste trabalho, nos referiremos à segunda e à terceira obras supracitas.

Agostinho expressa pelo termo signum o que nós chamamos signo ou sinal. Essa expressão aparece na Retórica forense latina, não para se referir às palavras, mas com o significado de indício, de sinal aparente ou provável de que uma coisa ocorreu quando falamos dos indícios de um crime, por exemplo. Assim, no de Inventione, Cícero (2002b, p. 100) define signum da seguinte forma:

\footnotetext{
O signo (signum) é o que cai sob um dos sentidos e indica (significat) uma coisa que parece sair do próprio fato: pode ter precedido, acompanhado ou seguido à ação, mas exige ser confirmado ou por um testemunho ou por uma prova mais sólida. Por exemplo, a sangue, a fuga, a palidez da face, o pó e as coisas que são do mesmo tipo.
}

Nessa citação, o termo signum está relacionado com eventos (a palidez da face, a presença de sangue nas vestes) e não com palavras. Na verdade, com a palavra signum, Cícero

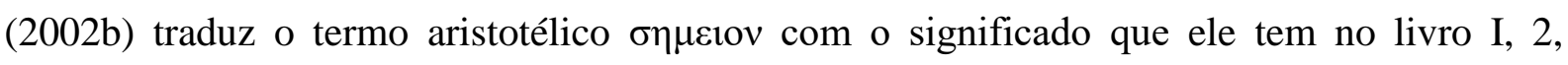
1357b, 1994, da Retórica de Aristóteles. Esse significado está explicitado nos Segundos analíticos (1979, II, 27, 70a 7-9), do seguinte modo: “o que coexiste com alguma coisa diferente dele, ou o que acontece antes ou depois que uma coisa diferente que aconteceu, é um signo de que uma coisa aconteceu ou existe".

Para se referir às palavras, Cícero (2002b) não emprega o termo signum senão os termos nota e verbum. Assim, os argumentos ex nota são aqueles que procedem a partir da etimologia de uma palavra. Cícero (2002b) afirma nos seus Tópicos, 10: Tum notatio, cum ex verbi vi argumentum aliquod elicitur (então, a etimologia permite obter um argumento a partir da força da palavra).

No Do mestre (1987, IV, 9), Agostinho define o que entende por signum do seguinte modo: "em geral chamamos sinais (signa) a tudo o que significa algo, e entre estes encontramos também as palavras". Afirma também que toda "palavra é sinal, mas nem todo sinal é palavra", tendo como exemplo de sinais não verbais as bandeiras militares e os sons das trombetas. Já no Da doutrina cristã ele dá, em primeiro lugar, a definição seguinte: "Denomino sinal (signum) a tudo o que se emprega para significar alguma coisa além de si mesmo (AGOSTINHO, 1957, I, 2,2)”. Mais adiante, no livro II, refere também: 
O sinal é, portanto, toda coisa que, além da impressão que produz em nossos sentidos (praeter speciem quam ingerit sensibus) faz com que venha ao pensamento outra ideia distinta (aliud aliquid ex se faciens in cogitationem venire). Assim, por exemplo, quando vemos uma pegada, pensamos que foi feita por um animal. Ao ver fumaça, percebemos que embaixo deve haver fogo. (AGOSTINHO, 1957, II, 1,1).

Outrossim, Agostinho faz a distinção entre sinais naturais e sinais convencionais:

Entre os sinais, alguns são naturais e outros convencionais. Os naturais são os que, sem intenção nem desejo de significação, dão a conhecer, por si próprios, alguma outra coisa além do que são em si. Assim, a fumaça é sinal de fogo. Ela o assinala sem ter essa intenção, mas nós sabemos, por experiência, observando e comprovando as coisas, que ao aparecer a fumaça haverá fogo embaixo [...]. Sinais convencionais (data signa) são os que todos os seres vivos mutuamente se trocam para manifestar - o quanto isso lhes é possível - os movimentos de sua alma, tais sejam as sensações e os pensamentos. Não há outra razão para significar, isto é, para dar um sinal, a não ser expor e comunicar ao espírito dos outros, o que se tinha em si próprio, ao dar o sinal. É sobre esse tipo de sinais e no que se refere aos homens que determinei examinar e estudar aqui. E por que os sinais que nos foram comunicados por Deus, e que se encontram nas Santas Escrituras, foram-nos comunicados pelos homens que as escreveram. (1957, II, 1,2).

Agostinho pensa os sinais convencionais não como o fruto de uma convenção ou acordo social, mas como o resultado da intenção de comunicar. Prova disso é que ele se refere ao fato de que muitos animais podem produzir esse tipo de sinais sem eles formarem sociedades. Entre os data signa encontramos os movimentos das mãos e da cabeça com que os homens expressam seus pensamentos, os gestos dos cômicos, os estandartes e insígnias militares, os sons dos instrumentos militares e as palavras, o que quer dizer que nem todo sinal convencional é verbal. Mas, sem dúvida, são as palavras os que têm a preeminência: “As palavras, com efeito, obtiveram entre os homens o principal lugar para a expressão de quaisquer pensamentos, sempre que alguém quer manifestá-lo" (AGOSTINHO, De doctrina II, 3,4).

A partir dessas citações podemos afirmar que o significado que tem o termo signum para Agostinho é diferente do que lhe outorgara Cícero (2002b), por exemplo. Darell Jackson (1969) argumentou, ao nosso ver de forma convincente, que no termo signum Agostinho reúne o significado dos dois termos estoicos $\sigma \eta \mu \alpha \iota v o v^{2}$ e $\sigma \eta \mu \varepsilon \iota^{3}{ }^{3}$ (DARELL JACKSON, 1969, p 45-49). O primeiro pode ser traduzido como aquilo que significa, quer dizer, o significante. Os estoicos o conceituam dentro do quadro de uma Semântica que distingue o

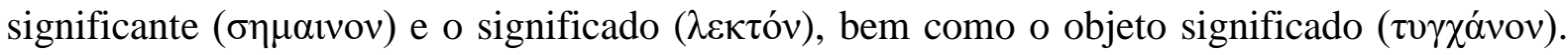

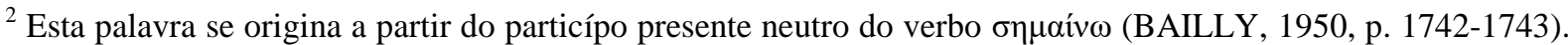
Podemos traduzi-la por "significante".

${ }^{3}$ Trata-se de um substantivo neutro (BAILLY, 1950, p.1743)
} 
Sexto Empírico (apud KNEALE; KNEALE, 1980, p. 133), por sua vez, nos informa sobre a semântica dos estoicos assim:

\begin{abstract}
Os estoicos afirmam que estes três elementos estão conectados: o significado, o significante e o objeto. Desses três elementos, o significante corresponde à fala, como, por exemplo, "Dion"; o significado é o que se mostra por meio dessa palavra e que nós compreendemos como subsistente no nosso pensamento, mas que os bárbaros não entendem mesmo que tenham ouvido a palavra; o objeto, por último, é o que existe de forma física fora de nós, como por exemplo, o próprio Dion. Dois desses elementos são corpóreos, a saber, a palavra e o objeto, ao passo que um deles é incorpóreo: o significado [lektón] que é verdadeiro ou falso.
\end{abstract}

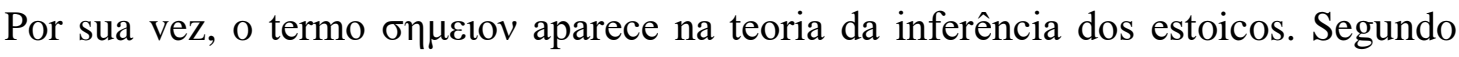

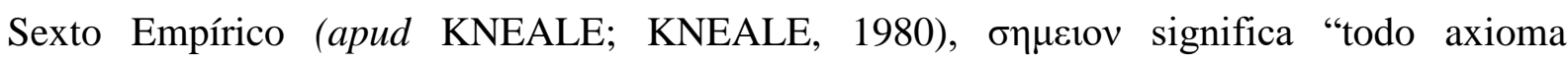
(proposição) $^{4}$ que, em um condicional válido, forma o antecedente e mostra o consequente" como, por exemplo, "ela tem leite no seio" mostra, na proposição condicional "se ela tem leite no seio então deu a luz”, o consequente “deu a luz" (KNEALE; KNEALE, 1980, p.134; O'TOOLE; JENNINGS, 2004, p.468).

Se voltarmos nossa atenção para as duas definições de signo (sinal), citadas acima, dadas por Agostinho em Da doutrina cristã , observamos que na primeira o termo signum se aproxima do significado do termo estoico on $\mu$ alvov e, na segunda, do significado do termo

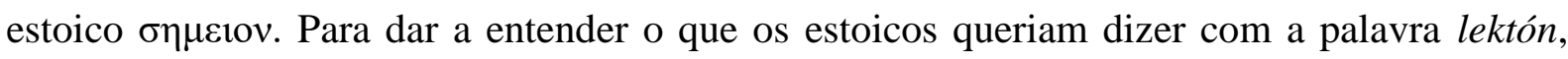
Agostinho usou a palavra dicibile (DARELL JACKSON, 1969, p. 46-49). Por último,

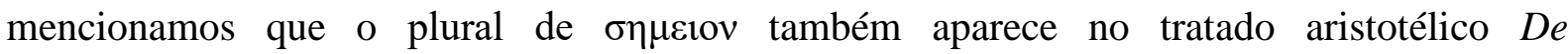
interpretione (1995, I, 16 a 4-8), em que Aristóteles afirma que a relação entre palavras e coisas está mediada pelos estados da alma. Mas aqui, o termo aristotélico tem outro significado, um significado próximo ao do termo oๆ $\mu$ aıvov dos estoicos.

Nesse sentido, o conceito de signo que Agostinho quer retratar aproxima-se dos conceitos que os estoicos usaram na suas teorias lógicas e semânticas, mas de uma maneira diferente, com definições mais gerais, o que nos obriga a estar atentos para não nos confundir sobre o que ele afirma.

\footnotetext{
${ }^{4} \mathrm{O}$ termo "axioma" não corresponde exatamente ao que chamamos hoje proposição. Pois o axioma é um $\lambda \varepsilon \kappa \tau$ ó e este incorpora aspectos de sua enunciação tais como o tempo quando foi dito. Para as diferenças entre axioma, no sentido dos estoicos, e proposição, no sentido contemporâneo, ver Kneale; Kneale (1980, p. 145-151).
} 


\section{SIGNOS E LINGUAGEM NO DO MESTRE}

O Do mestre (ou De magistro) expõe um diálogo entre Agostinho e seu filho Adeodato. O tema dele faz-nos lembrar do Menon de Platão. Com efeito, nesse texto, Agostinho se ocupa da origem do conhecimento e do que pode ser aprendido e ensinado. Contudo, em vez de recorrer à teoria da reminiscência para explicar a origem do conhecimento, Agostinho se serve do que ele chama luz interior da mente, cuja fonte é Cristo.

O Do mestre não é um diálogo que possa ser lido com facilidade. Quando a reflexão de Agostinho parece nos levar a um lado, ele desanda todo o caminho e volta a retomar os problemas a partir do início, chegando a conclusões opostas às que primeiro estabelecera.

$\mathrm{O}$ autor parte do pressuposto de que a função principal da linguagem é ensinar ou aprender. No Do mestre, compara a expressividade da linguagem verbal com a de outros sistemas semióticos tais como a linguagem gestual dos surdos e as pantomimas dos atores. Pareceria que esses sistemas têm o mesmo poder de expressividade que a linguagem verbal, uma vez que por meio de gestos não apenas as coisas visíveis, mas ainda os sons e os sabores podem ser expressos (AGOSTINHO, 1987, III, 5). No entanto, para ter certeza maior sobre isso, cumpre analisar com mais detalhe a natureza da linguagem verbal.

Uma análise superficial estabeleceria que cada palavra indicaria uma coisa. Assim a palavra "parede" designaria aquela parede branca para a qual apontamos nosso dedo. Mas consideremos o seguinte verso da Eneida: Si nihil ex tanta superis placet urbe relinqui ${ }^{5}$. À palavra urbe (cidade) podemos associar uma determinada cidade, Troia, como sendo a coisa que ela indica. Mas que associaremos com a palavra nihil (nada) dado que ela não se refere a nada? E com a preposição ex (de)? Só podemos dizer que ela significa o mesmo que a preposição latina de. Isto é, damos o significado de uma palavra (ex) por meio do significado de outra palavra (de). Então existem palavras cujo significado pode ser dado apontando ao objeto que elas indicam (esse é o caso de "parede"), existem palavras cujo significado só pode ser dado por meio do significado de outras palavras (como ex) e finalmente há palavras como nihil que sabemos que significam, mas são tais que não podemos explicar por que elas significam (AGOSTINHO, 1987, II,4). Além disso, encontramos palavras que se significam a si mesmas. Por exemplo, quando dizemos "signo" (signum), dizemos uma palavra (verbum) e

\footnotetext{
${ }^{5}$ Se nada aos deuses agrada que fique de tão grande cidade (Virgílio, Eneida, II, 659).
} 
uma palavra é um signo ${ }^{6}$. O mesmo acontece ao dizer "palavra" porque expressamos uma palavra (AGOSTINHO, 1987, IV, 10, p. 299). Finalmente existem palavras que parecem se significar reciprocamente. Ao dizer "nome" expressamos uma palavra, porque essa expressão é proferida mediante a articulação da voz e tem um significado ${ }^{7}$. Por sua vez "palavra" é o nome de um determinado tipo de signos, a saber, os signos verbais (AGOSTINHO, 1987, IV, 9, p. 298-299) ${ }^{8}$.

No entanto, há uma diferença clara entre "nome" e "palavra". Tudo o que é um nome é uma palavra, mas não toda palavra pode ser considerada um nome, por exemplo, ex é uma palavra, mas não é um nome, dado que não podemos identificar o que essa palavra nomearia. Vemos então que os signos linguísticos remetem às coisas do mundo, mas também ao próprio código linguístico das palavras, constituindo uma metalinguagem. Assim, usando a terminologia de Agostinho, há palavras que significam coisas, como "parede" e outras, como é o caso de "ex", que significam palavras, no caso " $d e$ "9.

Quiçá essas análises de Agostinho possam deixar insatisfeito o leitor contemporâneo. O Santo tem consciência da diferença entre linguagem e metalinguagem, entre significante e significado, contudo não possui nem uma notação para expressá-la, diferentemente de nós que usamos aspas para marcar as expressões metalinguísticas, tampouco os conceitos adequados para isso.

Falta em Agostinho uma caracterização acurada do que seja um nome e da diferença entre nome próprio e nome comum. Além disso, não se encontra no Do mestre a distinção entre extensão e compreensão de um nome comum. Os diferentes conceitos que a Semântica contemporânea acunhou, como os de significado, sentido, referência são todos reunidos por Agostinho no verbo "significar". Também, falta-lhe a distinção entre termos categoremáticos e termos sincategoremáticos; Agostinho parece pensar que todo termo categoremático é um nome.

\footnotetext{
${ }^{6}$ Nós diríamos hoje: o significante "signo" é uma palavra e uma palavra é um signo. Mas não podemos dizer: o significante "leão" é um leão.

${ }^{7}$ Diz Agostinho: Ergo, et nomen verbum est, quandoquidem id videmus cum aliquo significatu articulata voce proferri (AGOSTINHO, 1987, IV, 9). "Nome" como significante é uma palavra.

${ }^{8}$ Agostinho pergunta a Adeodato: Concedis igitur iis duabus syllabis quas edimus, cum dicimus: Verbum, nomen quoque significari, et ob hoc illud huius signum esse (AGOSTINHO, 1987, IV, 9). "Palavra" como significante se usa como nome dos sinais verbais.

${ }^{9}$ No De doctrina christiana, a semântica de Agostinho é mais complexa: ele distingue entre as palavras (voces, verba), o significado (dicibile) e a coisa (res) apontada por esse significado, aproximando-se assim da semântica dos estoicos (ver DARELL JACKSON,1969, p. 45-49).
} 
No início do Do mestre, Agostinho diz que nem toda palavra é nome, mas depois, a partir de V, 14, volta para trás, tentando interpretar como nomes diferentes expressões que em princípio não consideramos nomes como o verbo est e as conjunções si (se) e quia (porque) ${ }^{10}$.

Consideremos o caso mais simples de significação. Suponhamos estar ensinando a uma criança o significado da palavra "parede". Como faremos? Apontamos nosso dedo para uma parede. Mas então para mostrar o significado de uma palavra teremos usado um sinal ou signo porque o dedo que estamos apontando faz o papel de sinal. Disso resulta que só podemos mostrar (ensinar) o que uma palavra significa usando outro signo, sem poder exibir diretamente a coisa mesma.

Signos se mostrariam somente por meio de signos. Haverá algo que possa ser mostrado sem signos? Queremos ensinar o significado da palavra “caminhar". Aqui encontramos uma forma de mostrar ostensivamente a um interlocutor o significado de uma palavra sem usar outro signo, verbal ou de qualquer outro tipo: basta-nos efetuar a ação de caminhar. E o mesmo poderia ser feito em relação às palavras que significam ações que nós podemos realizar tais como correr, comer, beber etc. Mas aqui surgem também dificuldades. Há nesse caso o que chamaríamos hoje uma indeterminação da referência. Se alguém nos perguntar o que significa "caminhar" podemos começar a andar e até andar mais depressa para ressaltar nossa ação. Mas aí então nosso interlocutor poderia acreditar que "caminhar" significa quanto andamos ou andar depressa ou até poderia pensar que nós não queremos responder-lhe. De tudo o arrazoado - diz Agostinho - "concluiu-se que nada se pode ensinar sem sinais..." (AGOSTINHO, 1987, X, 31).

Eis aqui que Agostinho, após ter estabelecido essas conclusões, começa a duvidar delas e empreende outro caminho que o levará a resultados opostos aos até então obtidos. Se antes Agostinho estabelecera não ser possível alcançar o conhecimento de nenhuma coisa sem usar signos concluindo que as palavras remetem sempre a signos (a palavra "parede" ao sinal de apontar com o dedo, a palavra ex à palavra de), agora Agostinho vai nos dizer que para saber se algo é um signo devemos conhecer antes a coisa que esse signo indica. Afirma: “[...] se me for apresentado um sinal e eu não me encontrar na condição de não saber de que coisa é sinal, este nada poderá ensinar-me” (AGOSTINHO, 1987, X, 33).

\footnotetext{
${ }^{10}$ O latim não tinha advérbio de afirmação e para expressá-la usava-se o verbo sum. Por exemplo, a frase do Evangelho: Non erat in Christo Est et Non, sed Est in illo erat (2 Cor, 1, 19), deve se interpretar assim: Não havia em Cristo o sim e o não, mas somente havia nele o sim.
} 
Isso permite a Agostinho concluir que "[...] mais através do conhecimento da coisa se aprende o sinal do que se aprende a coisa depois de ter o sinal" (AGOSTINHO, 1987, X, 33). Aplicando essas conclusões à linguagem verbal podemos dizer que "[...] aprendemos o valor da palavra (vim verbi), ou seja, o significado que está escondido no som através do conhecimento ou da própria percepção da coisa significada; mas não a própria coisa através do significado" (AGOSTINHO, 1987, X, 34).

Entendemos que esse retorno que Agostinho faz em sua argumentação se dá pelo fato de ter sido durante muito tempo professor de Retórica. A Retórica é uma disciplina que ensina como argumentar em favor dos dois lados de uma questão ${ }^{11}$, in utramque partem dizia-se na Retórica latina. Aqui, no Do mestre, vemos que Agostinho argumentou tanto para afirmar que o conhecimento das coisas só é possível mediante o emprego de signos quanto para afirmar que o conhecimento dos signos só é possível se conhecermos previamente as coisas que esses signos indicam ${ }^{12}$. Em um caso estabelecemos, no processo de conhecimento, a prioridade dos signos sobre as coisas referidas por eles, no outro caso a prioridade das coisas sobre os signos.

A leitura do De mestre mostra que Agostinho se debruçou sobre vários temas da Semiótica: o papel dos signos em geral e da linguagem em particular no conhecimento das coisas; o conhecimento das coisas para poder identificar um signo como tal; a relação entre signos e outros signos; a relação entre signo e coisa designada, a possibilidade de expressar um sistema semiótico por meio de outro sistema semiótico.

A discussão desses assuntos serve, para Agostinho, como degraus de uma escada que lhe permite chegar ao lugar a partir do qual poderá formular as questões que são as que preferencialmente lhe interessam responder naquela obra: $\mathrm{O}$ que podemos aprender mediante palavras?; o que podemos ensinar por meio das palavras?; quem é nosso verdadeiro mestre?

\section{SIGNOS E COISAS NO DA DOUTRINA CRISTÃ}

O tema de Da doutrina cristã é como entender a mensagem das Sagradas Escrituras e como ensiná-lo aos fiéis. Diz Agostinho: "há duas coisas igualmente importantes na

\footnotetext{
11 “As outras artes não obtêm conclusões sobre contrários por meio de silogismos, senão só fazem isso a Dialética e a Retórica porque as duas se aplicam igualmente aos casos contrários" afirma Aristóteles em Retórica (1994, 1355 a, 35).

${ }^{12}$ Segundo Horn (2006, p.13), Agostinho retoma um argumento aporético, tirado do ceticismo pirrônico: quem tenta aprender algo na base de palavras tem ou bem de já saber com o que as palavras se relacionam, e desse modo é mostrado que ele não pode tê-lo aprendido somente através delas, ou, porém, é tal que não sabe com o que as palavras se relacionam. Nesse último caso, ele também não pode aprendê-lo através delas.
} 
exposição das Escrituras: a maneira de descobrir (modus inveniendi) o que é para ser entendido e a maneira de expor (modus proferendi) com propriedade o que foi entendido" (AGOSTINHO, 1957, I, 1, 1). "Descobrir" e "expor" remetem a duas partes da Retórica clássica, à invenção (inventio), dedicada às estratégias para encontrar argumentos para defender uma causa; e à elocução (eloqutio), que se ocupa de como apresentar os argumentos achados.

Da doutrina cristã pode ser considerada uma das primeiras obras de Retórica cristã em língua latina. Mas não é apenas isso, é também um manual de exegese bíblica. Como essas duas finalidades se relacionam tem sido analisado por alguns intérpretes dessa obra.

O texto de Agostinho se compõe de quatro livros. O primeiro apresenta uma síntese dogmática e moral da doutrina cristã e estabelece os princípios básicos da exegese das Escrituras. O livro segundo entra na Semiótica. Seu título é: Sobre os sinais a serem interpretados na Escritura. O terceiro se refere às dificuldades para interpretar as Escrituras; e o quarto se ocupa da forma como deve ser exposta a doutrina cristã pelo pregador religioso.

Em duas partes de Da doutrina cristã Agostinho define o que é um signo (sinal). No livro I escreve assim:

\footnotetext{
Toda doutrina reduz-se ao ensino das coisas e ao dos sinais. Mas as coisas são conhecidas por meio dos sinais. Portanto, acabo de denominar coisas a tudo o que não está empregado para significar algum outro objeto como, por exemplo, uma vara, uma pedra, um animal ou outro objeto análogo. Não me refiro, contudo, àquela vara da qual lemos que Moisés atirou às águas amargas para diluir sua amargura (Ex 15,25). Nem à pedra que Jacó pôs debaixo da cabeça, como almofada $(\mathrm{Gn} 28,11)$. Nem àquele cordeiro que Abraão imolou no lugar de seu filho (Gn 22,13). Esses objetos, de fato, são coisas, mas nas circunstâncias mencionadas tornaram-se ao mesmo tempo sinais de outras coisas [..] Ninguém emprega as palavras a não ser para significar alguma coisa com elas. Daí se deduz que denomino sinais a tudo o que se emprega para significar alguma coisa além de si mesmo. (AGOSTINHO, 1957,I, 2, 2).
}

Aqui Agostinho contrapõe coisas e signos. A diferença entre elas não está na sua composição material senão no significado que têm para nossa mente. Encontramos um cordeiro e ele nada mostra para nossa mente, além de sua presença. Em contrapartida o cordeiro de Abrão significava, para ele, seu filho que iria ser imolado como prova de obediência a Deus. A visão desse cordeiro apontava para outra coisa além de si mesmo. Por outro lado, Agostinho volta a expressar a tese apresentada na primeira parte do Do mestre segundo a qual só conhecemos as coisas por meio de signos.

No livro II, do Da doutrina cristã Agostinho escreve o seguinte: 
O sinal é, portanto, toda coisa que, além da impressão que produz em nossos sentidos, faz com que nos venha ao pensamento outra ideia distinta. Assim, por exemplo, quando vemos uma pegada, pensamos que foi impressa por animal. Ao ver fumaça, pensamos que embaixo deve haver fogo. Ao ouvir a voz de um ser animado, damo-nos conta do estado de seu ânimo. Quando soa a corneta, os soldados sabem se devem avançar, retirar-se ou fazer alguma outra manobra exigida pelo combate. (AGOSTINHO, 1957, II, 1, 1).

Dessa forma, as coisas são simplesmente coisas até o momento em que recebem uma atribuição de significado ou de representação dada pelo homem. A partir desse instante as coisas passam a ser signos, ou melhor, passam a ser coisas-signos. Agostinho faz, na obra $D a$ doutrina cristã, no seu tema de estudo, vários recortes: primeiro diz que vai se ocupar dos signos convencionais (data signa). Depois Agostinho realiza um segundo recorte: só se ocupará com os signos convencionais produzidos pelos seres humanos. Terceiro recorte, este implícito: ele se ocupará dos signos verbais e, finalmente, quarto recorte, daqueles que estão nas Sagradas Escrituras e que nos foram comunicados por os que as escreveram.

A distinção entre signos convencionais e naturais parece ser, ao que tudo indica, uma novidade introduzida por Santo Agostinho (TODOROV, 1996, cap. 1) ${ }^{13}$. Dentre os signos convencionais os mais importantes são as palavras. Com efeito, segundo Agostinho, a linguagem verbal tem um privilégio sobre os demais sistemas semióticos que consiste em que o que os outros sistemas fazem conhecer pode ser dado por meio das palavras, mas o que as palavras significam não pode ser dado por meio dos outros sistemas semióticos.

Certamente - afirma Agostinho - "Cristo deu um sinal através do olfato pelo perfume do unguento derramado em seus pés" (Jó 12, 3.7). Igualmente, por meio do tato deu um sinal, quando a mulher tocando a orla de sua veste recebeu a cura (Mt 9, 21). Pelo sentido do paladar, Jesus também significou sua vontade pelo sacramento de seu corpo e sangue gostados previamente por ele (Lc 22, 19-20). Mas a maioria dos signos usados pelos homens para expressar seu pensamento são palavras.

\footnotetext{
13 Ela não se encontra em Aristóteles. Nos Primeiros analíticos 1979, II, 27, 70a 7-9), Aristóteles define signo ( $\sigma \eta \mu \varepsilon i o v)$ assim: é a coisa cuja existência ou produção acarreta a existência ou produção de outra coisa, seja anterior ou posterior. Os signos aparecem como premissas de entimemas. O signo supõe uma relação entre duas coisas. Se a relação é necessária o signo se denomina tekmérion. Na Retórica I, 2.6, dá os seguintes exemplo de signos necessários: a presença de leite no seio de uma mulher é signo necessário de que deu à luz, a presença de febre é signo necessário de doença. Se a relação não é necessária, o signo não tem um nome especial e expressa somente uma probabilidade como, por exemplo, alguém dizer que é um signo de que uma pessoa tem febre o fato de que ela respira agitadamente. Em Aristóteles (1979), a distinção entre signo necessário e não necessário tem a ver com a natureza do vínculo entre signo e designado e não com a presença ou ausência de uma intenção consciente na produção do signo.
} 
Para Agostinho, "qualquer desses sinais: o cheiro do unguento, o contato com a veste, o sabor da hóstia podem ser certamente dados e conhecidos com palavras, mas as palavras não poderiam ser dadas a entender com aqueles sinais" (AGOSTINHO, 1957, II, 3, 4).

Em outra passagem do Da doutrina cristã reforça a superioridade da linguagem verbal, enquanto poder de expressão dos pensamentos, sobre a linguagem gestual, mostrando que esta última precisa das palavras para poder atingir sua finalidade comunicativa. Diz Agostinho (1957, II, 26, 38):

\begin{abstract}
realmente, as mímicas que os histriões fazem ao dançar não teriam sentido por sua própria natureza, mas o têm pela convenção e consentimento dos homens. Outrora em Cartago, quando um pantomimo dançava, um apresentador público anunciava o que o dançarino queria exprimir. Muitos anciãos lembram-se ainda desse pormenor e nós os ouvimos contar. E neles devemos crer, porque como isso não se faz mais, só os idosos compreendem o significado dos gestos dos atores. Se alguém entrar no teatro sem estar iniciado nessas farsas, não compreenderá grande coisa da intriga, se não tiver um bom vizinho para lhe dar algumas explicações (AGOSTINHO,
\end{abstract}

Vimos que no Do mestre, Agostinho argumentou que para entender o significado de um signo devemos conhecer a coisa que esse signo indica. Como o interesse de Agostinho, no Da doutrina cristã, está no conhecimento do significado das palavras da Escritura, ele considera necessário conhecer as coisas de que a Escritura fala. Em primeiro lugar os seres da natureza, animais, plantas e pedras mencionados nela.

Segundo Agostinho (1957, II, 17, 24), "a ignorância da natureza das coisas dificulta a interpretação das expressões figuradas, quanto estas se referem aos animais, pedras, plantas ou outros seres citados frequentemente nas Escrituras e servindo como objeto de comparações".

\title{
4 A INTERPRETAÇÃO DOS SIGNOS VERBAIS EM DA DOUTRINA CRISTÃ
}

A terceira tradição hermenêutica, conhecida por Santo Agostinho, era a relacionada com a interpretação dos textos bíblicos. Dentro da tradição cristã, o primeiro em desenvolver uma hermenêutica dos textos religiosos foi Clemente de Alexandria no século II DC.

Clemente desenvolveu a interpretação alegórica da Bíblia cristã, continuada depois por Orígenes, também de Alexandria, Santo Ambrósio e, em parte, por Agostinho. Aristóteles e os tratadistas greco-latinos de Retórica dissertaram sobre as expressões verbais com sentidos figurados só em relação aos signos verbais. Clemente de Alexandria foi além deles porque 
reconheceu sentidos figurados também em outros sistemas semióticos diferentes da linguagem verbal, como a escrita hieroglífica dos egípcios (TODOROV, 1996, p. 33). Outro exemplo dados por Clemente de Alexandria é o de

\begin{abstract}
essas formalidades ocorridas entre os romanos para os testamentos, como a presença das balanças e das moedas de pequeno valor para evocar a justiça: uma cerimônia de abertura para representar a partilha dos bens, e o toque nas orelhas para convidar a servir de mediador. (STROMATE, V. 55. 4 apud TODOROV, 1996, p.33).
\end{abstract}

Assim Clemente aplicou a distinção entre sentido próprio e sentido figurado a signos diferentes das palavras. Como os signos com sentido figurado podem ser verbais ou não verbais, podem ser reconhecidos não apenas pela audição senão também pela visão e o tato.

A tese central de Agostinho, na Da doutrina cristã, é que a res (verdades a serem descobertas nas Escrituras) foi transmitida nas Sagradas Escrituras por meio da linguagem verbal (verba - signo verbal) às vezes usando expressões que devem ser consideradas literalmente e em outros casos por expressões que têm um sentido figurado, o que se traduz em uma forma de interpretação que ora pende para a letra do texto sagrado, ora para seu espírito (GINZBURG, 2010).

Para Agostinho, a revelação da res necessita de um olhar mais sensível por parte do pregador a fim de desvendar os desvios de sentido proporcionados pela linguagem camuflada. Quer dizer, há uma linguagem simbólica, indireta, em vários trechos das Sagradas Escrituras que exige uma interpretação adequada. A distinção entre signo próprio e signo figurado é estabelecida por Agostinho da forma seguinte:

\footnotetext{
Com efeito, os signos são próprios ou figurados. São chamados próprios quando empregados para designar os objetos para os quais foram convencionados. Por exemplo, dizemos: boi, e relacionamos com o animal que todos os homens de língua latina denominam por esse nome. Os signos são figurados ou metafóricos, quando as mesmas coisas, que denominamos com seu termo próprio, são também tomadas para significar algo diferente. Por exemplo, dizemos: boi e por essa palavra entenderemos o animal que se costuma chama por esse nome e, além disso, entenderemos que se alude ao pregador do evangelho, conforme o deu a entender a Escritura na interpretação do Apóstolo, que disse: "Não amordaçarás o boi que tritura o grão" (1Cor 9,9). (AGOSTINHO, 1957, II, 10, 15).
}

A diferença entre signo próprio e signo figurado está dada pela complexidade da relação entre signo e designado. No casso do signo próprio essa relação é direta, no caso do signo figurado o designado (o boi) se transforma por sua vez em signo de outro designado (o pregador). Nem sempre, a clareza (perspicuitas) na interpretação do texto bíblico é alcançada, 
pois podem ocorrer aberturas para mais de um sentido a ser levado em conta. Aí entra a obscuridade (obscuritas) linguística que Santo Agostinho visa a resolver. Essa obscuridade, porém, tem sua utilidade, pois afirma Agostinho (1957, II, 6, 7): “os que leem a Escritura inconsideradamente enganam-se com as múltiplas obscuridades e ambiguidades, tomando um sentido por outro. Nem chegam a encontrar, em algumas passagens, alguma interpretação”.

Conforme o uso, os elementos do código linguístico podem assumir várias significados. Isso, por vezes, causa ambiguidades ou até erros de interpretação quando se toma um signo com seu sentido próprio sem observar que ele tem um sentido figurado. Já a Retórica clássica considerara que o sentido próprio de uma expressão é o sentido para o qual ela foi criada como signo, e o sentido figurado ou transposto é aquele sentido modificado que se agrega a uma expressão. Nesse segundo emprego da linguagem, inserem-se as figuras ou tropos. Os tropos podem gerar a obscuridade (obscuritas) que, conforme Lausberg (1967), estudioso contemporâneo da Retórica, constitui um erro contra a clareza do discurso.

Para uma leitura e interpretação correta da Sagrada Escritura, deve-se discernir se a expressão é própria ou figurada:

\begin{abstract}
Portanto, o que mais nos interessa é investigar se a expressão que se deseja entender está em sentido próprio ou em sentido figurado. Quando se descobre que ela é figurada, torna-se fácil, graças às regras que expressamos no Livro I, ao tratar das coisas (De rebus), considerá-las por todos os lados até chegar a seu verdadeiro sentido. Isso será facilitado, quando, ao emprego de tais regras, o exercício da piedade vier dar maior força. Em conclusão, conheceremos se uma expressão é própria ou figurada observando as regras anteriormente expostas. (AGOSTINHO, 1957, III, 24, 34a).
\end{abstract}

Mas como saber se uma expressão deve ser tomada em sentido próprio ou em sentido figurado? Agostinho responde da seguinte maneira: “Tudo o que na palavra divina não puder se referir ao sentido próprio, nem à honestidade dos costumes, nem à verdade da fé, está dito que devemos tomar em sentido figurado" (AGOSTINHO, 1957, III, 10, 14).

Chamemos MI a essa Máxima Interpretativa. Para Agostinho, como para os outros autores cristãos, o Antigo Testamento é uma antecipação das promessas mencionadas no Novo Testamento. Com efeito, a Lei de Moisés e os Livros dos profetas devem ser considerados como um conjunto de signos cuja interpretação só se tornou clara com a vinda de Cristo.

Dada a continuidade entre os dois Testamentos, como interpretar determinados trechos do Antigo Testamento cujo significado literal parece ser contraditório com a fé cristã ou com à 
honestidade dos costumes? O intérprete das Sagradas Escrituras se defrontará com preceitos do Antigo Testamento que aparentemente contradiriam o conteúdo dos Evangelhos. Haverá que admitir que a Lei de Moisés e dos profetas contradiz a Lei de Cristo? Para dissolver essa contradição aparente se deve supor que muitos trechos do Antigo Testamento têm um sentido figurado e adotar a máxima que designamos acima MI. Mas devemos ser precavidos ao adotar essa máxima de forma irrestrita porque "o gênero humano propende a julgar os pecados não pela gravidade da própria paixão, mas, ao contrário, pelo costume e uso do seu próprio tempo" (AGOSTINHO, 1957, III, 10, 15) e, então, "sucede, na maioria das vezes, que cada um dentre os homens somente julga condenáveis os atos que as pessoas do seu país e seu tempo tomaram o hábito de reprovar e condenar" (AGOSTINHO, 1957, III, 10, 15). Se não formos precavidos poderíamos fazer uma interpretação que hoje chamaríamos anacrônica: julgaríamos os costumes dos antigos israelitas segundo os nossos. E, assim, se não temos essa precaução interpretaremos de forma figurada, trechos que, na verdade, devem ser interpretados de forma literal.

Agostinho (1957, III, 5, 9) nos adverte que "o homem que segue só a letra toma como próprias as expressões metafóricas, e nem sabe dar a significação verdadeira ao que está escrito com palavras próprias".

Dado que a interpretação das Sagradas Escrituras é uma tarefa complexa, seja pelo fato de que o texto bíblico muitas vezes está expresso em uma linguagem figurada, seja pelas ambiguidades presentes nele, coloca-se a seguinte questão: quais são as interpretações admissíveis?

Nas Confissões, Livro XII, Agostinho aborda esse problema ao tentar interpretar os primeiros versículos do Gênesis cuja autoria o Santo atribui a Moisés. Duas perguntas se colocam: "uma é sobre a veracidade das afirmações em si mesmas; outra, se eles, os intérpretes, estão em desacordo com a intenção de quem as enuncia. Uma coisa é inquirir a verdade sobre a criação, outra procurar saber o que Moisés quis significar" (AGOSTINHO, 1987, p. 249). Para responder essas questões, Agostinho estabelece a distinção entre compreender e acreditar.

Podem ser aceitas todas as interpretações nas quais possamos acreditar, mesmo que não possamos compreendê-las. De fato mesmo que Moisés nos aparecesse e dissesse "este é o meu pensamento" não o compreenderíamos, mas somente acreditaríamos nele (AGOSTINHO, 1987, p. 251). Todas as interpretações nas quais possamos acreditar têm sua parte de verdade, o que expressa Agostinho nesta belíssima passagem: 


\begin{abstract}
A fonte (cujas águas se aglomeram) num pequeno reservatório é (depois) mais abundante e fornece o caudal a diversos regatos para uma extensão mais ampla do que a de qualquer deles. Estes, oriundos da mesma fonte espalham-se por muitos lugares. Assim, de modo idêntico, a narração [os primeiros versículos do Gênesis] de vosso Dispensador, que havia de ser útil a todos os intérpretes, de poucas e modestas palavras faz deslizar correntes de verdade cristalina. Destas, cada um pode haurir a parte de verdade de que é capaz, uns de uma maneira, outros doutra, para a desenvolverem em seguida por longos rodeios de expressão. (AGOSTINHO, 1987, p. 252).
\end{abstract}

\title{
CONCLUSÕES
}

Agostinho foi um dos primeiros autores, se não o primeiro, que pensou a linguagem como um sistema de signos, construído pelos homens, com o fim de transmitir seus pensamentos. Abordou vários problemas que fazem parte da Semiótica: a relação entre signo e designado; a especificidade da linguagem em relação a outros sistemas de signos; a expressão de signos por meio de outros signos; a autorreferência de alguns signos; e a distinção entre o sentido direto de um signo e seu sentido figurado. No entanto, como sua preocupação principal era a interpretação das Sagradas Escrituras e a transmissão da verdade cristã, ele privilegiou o signo verbal, isto é, a palavra.

O elemento central para a interpretação das Sagradas Escrituras é a palavra como objeto significativo em sua rede de relações, quais sejam: a palavra por ela mesma, a palavra na frase, a palavra no parágrafo, a palavra para certa cultura, a palavra no discurso do orador. A palavra em si ou em sua relação na frase ou mesmo no parágrafo, dependendo do modo como se articula com os demais componentes, pode assumir um significado diferente do seu habitual. Aqui é preciso dominar o conhecimento dos tropos ou figuras e reconhecer as ambiguidades.

Vemos, assim, que Agostinho desenvolveu princípios de interpretação que hoje são corriqueiros tanto dentro da semântica linguística quanto da filosófica: a ideia de que as palavras não devem ser tomadas isoladas, mas no seio de um discurso, a importância do contexto cultural para sua interpretação, a ideia de que os tropos e figuras não são apenas um enfeite do discurso, mas têm também um valor cognoscitivo.

As figuras apresentam a verdade de maneira velada, sugerindo primeiramente fé e oração por parte do pregador antes de este se lançar no estudo e transmissão da verdade das Sagradas Escrituras. Tendo o pregador adentrado no estudo, ele precisa ter conhecimentos 
basilares de gramática, retórica, enfim, conhecimentos das artes liberais para desenvolver bem o seu trabalho.

Nas obras Do Mestre e Da doutrina cristã encontramos os esboços de uma teoria geral sobre os signos. Agostinho fez a sínteses de várias tradições: semântica, de origem estoica, que distingue no signo linguístico os seguintes elementos: o verbum, a palavra considerada simplesmente como som e os significabilia, significados expressos pelas palavras e que são incorpóreos. Os significabilia se identificam com o lektón dos estoicos (DARREL JACKSON 1969; TODOROV, 1996; KNEALE; KNEALE, 1972, p. 131-151).

- retórica, com a distinção entre sentido próprio e sentido figurado de um signo.

- hermenêutica, associada às estratégias para desvendar os sentidos figurados em qualquer tipo de signos.

No De inventione Cícero (2002b) identificou três fontes de controvérsias relativas à interpretação dos textos jurídicos: a ambiguidade dos termos da lei, a contraposição entre o espírito e a letra da lei, a presença de leis contraditórias. As mesmas fontes são identificadas por Agostinho como causas de controvérsias sobre a interpretação da Sagrada Escritura. Mas as formas de resolver essas questões interpretativas são diferentes nos dois autores: em Cícero (2002) a Hermenêutica está subordinada à Retórica, pois o que o orador romano nos ensina é como obter a interpretação que seja mais apropriada para a defesa da causa pela qual se está advogando; em Agostinho é a Retórica que está subordinada à Hermenêutica uma vez que as doutrinas sobre os tropos e as figuras retóricas estão ao serviço da ação de desvendar a verdade contida nas Sagradas Escrituras.

\section{REFERÊNCIAS}

AGOSTINO, Santo. A trindade. Tradução de Nair de Assis Oliveira. 2.ed. São Paulo: Paulo, 1994.

AGOSTINO, Santo. Confissões. Tradução de J. Oliveira Santos, S.J. e A. Ambrósio de Pina S.J. São Paulo: Abril Cultural, 1987.

AGOSTINO, Santo. De la doctrina Cristiana. In: Obras de San Agustín, Tomo XV.

Tradução espanhola de Fr. Balbino Martín. Madri: Biblioteca de autores cristianos, 1957.

AGOSTINO, Santo. De magistro (Do mestre). Tradução de Angelo Ricci. São Paulo: Abril Cultural, 1987.

ANDREWS, James. Why Theological Hermeneutics Needs Rhetoric: Auguistine's De doctrina Christiana. International Journal of Systematic Theology. V. 12, n. 2, 2010. 
ARISTÓTELES. De interpretatione. In: Tratados de lógica. Ttrad. M. Candel Sanmartín. Madrid: Gredos, 1995.

ARISTÓTELES. Les secondes analytiques. Tradução J.Tricot. Paris: Vrin, 1979.

ARISTÓTELES. Retórica. Tradução de Quintín Racionero. Madrid: Gredos, 1994.

BAILLY, A. Dictionnaire grec-français. Paris: Hachette, 1950.

CÍCERO, Marco Túlio. Divisions de l' art oratoire. Topiques. Tradução francesa de Henri Bornecque. Paris: Les Belles Lettres, 2002a.

CÍCERO, Marco Túlio. De l' invention. Tradução francesa de Guy Achard. Paris: Les Belles Lettes, 2002 b.

DARRELL JACKSON, B. The theory of Signs in St. Agustine's De doctrina christiana. In: Revue des études Augustiniennes 15, p.9-49, 1969.

GINZBURG, C. The Letter Kills: On some Implications of 2 Corinthians 3:6. History and Theory, 2010, v. 49, n. 1, p.71-89.

HORN, Christoph. Agustinus. München: Beck, 1995.

HORN, Christoph. Agostinho-Teoria linguística dos sinais. Veritas, v51 n.1, p 5-17, 2006.

KNEALE, W; KNEALE, M. El desarrollo de la lógica. Madri: Tecnos, 1980.

LAUSBERG, Heinrich. Elementos de retórica literária. Tradução de R. M. Rosado Fernandes. 3. ed. Lisboa: Fundação Calouste Gulbenkian, 1967.

O'TOOLE, R.; JENNINGS, R. The megarians and the stoics. In: GABBAY, D; WOODS, J. Handobbok of the history of logic. Volume I. Elsevier, 2004

TODOROV, Tzvetan. Teorias do símbolo. Tradução de Enid Abreu Dobránszky. Campinas: Papirus, 1996. 